\title{
Deposition of a polymeric porous superhydrophobic thin layer on the surface of poly(vinylidenefluoride) hollow fiber membrane
}

\author{
A.L. Ahmad ${ }^{* 1}$, H.N. Mohammed ${ }^{1,2}$, B.S. Ooi ${ }^{1}$, C.P. Leo ${ }^{1}$ \\ ${ }^{1}$ University Sains Malaysia, School of Chemical Engineering, Engineering Campus, 14300 Nibong Tebal, Pulau Pinang, \\ Malaysia \\ ${ }^{2}$ Tikrit University, Chemical Engineering Department, Saladdin, Iraq \\ "Corresponding author: e-mail: chlatif@eng.usm.my
}

\begin{abstract}
Porous superhydrophobic layer of low-density polyethylene (LDPE) was created by a simple approach on the Poly(vinylidenefluoride) (PVDF) hollow fiber membranes. Acetone and ethanol mixtures with different volume ratios were used as the non-solvent on the coating surface. A 5:1 (v/v) acetone/ethanol ratio provided a porous surface with a $152^{\circ} \pm 3.2$ water contact angle. The high contact angle could reduce membrane wettability for better carbon dioxide capture when the membrane was used as gas-liquid contactor in absorption processes. To assess the effect of the created superhydrophobic layer, the pristine and modified membranes were tested in a $\mathrm{CO}_{2}$ absorption system for ten days. The results revealed that the absorption flux in the modified membrane was higher than that of pristine membrane.
\end{abstract}

Keywords: Superhydrophobic layer, PVDF, Gas-liquid contactor, $\mathrm{CO}_{2}$, Porous.

\section{INTRODUCTION}

In recent years, the greenhouse gases (e.g., $\mathrm{CO}_{2}$ ) in the atmosphere have become problematic because of their significant role in heat capturing. Almost half of the $\mathrm{CO}_{2}$ emissions to the atmosphere were produced by burning fossil fuels in power plants ${ }^{1}$. Therefore, a more efficient method to capture $\mathrm{CO}_{2}$ from flue gas streams is needed. Membrane technology, a promising approach to this issue due to its improved $\mathrm{CO}_{2}$ selectivity and separation capacity, has been used in membrane gas absorption systems. The original idea for $\mathrm{CO}_{2}$ absorption by membrane contactors was developed by Qi and Cussler; this initial idea was followed by several attempts to improve the efficiency of $\mathrm{CO}_{2}$ capture ${ }^{2-9}$.

Membrane gas absorption has several advantages over conventional absorption processes, such as a high mass transfer area and excellent operational flexibility, which may prevent flooding, loading, foaming and channeling problems. Membrane contactors are dominated by the membrane wetting problem, which refers to the increase in the membrane's mass transfer resistance when the absorption liquid penetrates the membrane pores. This increased résistance leads to a decrease in the mass flux over prolonged periods of operation.

Common absorbent liquids used in $\mathrm{CO}_{2}$ absorption systems are generally alkanolamine solutions. These amines can penetrate membrane pores more easily than water can due to their low surface tension, especially at high concentrations. At chariyawut et al. water and $2 \mathrm{M}$ monoethanolamine (MEA) were used separately as absorbents in microporous Poly(vinylidenefluoride) (PVDF) hollow fiber membranes ${ }^{\mathbf{1 0}}$. The results revealed that the $\mathrm{CO}_{2}$ flux remained constant for 15 days of testing using water as an absorbent, whereas the flux continuously decreased when MEA was used, reaching the value of approximately $57 \%$ of the initial flux after 15 days.

Different hydrophobic polymeric materials, such as polypropylene (PP), polyethylene (PE), polytetrafluoroethylene (PTFE) and PVDF, have been used to prepare hollow fiber membrane contactors for $\mathrm{CO}_{2}$ absorption. PTFE hollow fiber membranes maintained constant flux through $6600 \mathrm{hr}$ of testing in a $\mathrm{CO}_{2}$-MEA absorption system $^{11}$. Despite this advantage, the application of these membranes is limited due to the high cost of production. Many studies have sought to overcome the membrane wetting problem using inexpensive materials. Different PVDF hollow fiber membrane structures was prepared using non-solvent additives in the spinning polymer dope to produce a porous membrane with a small pore size to reduce the wetting resistance, 12, 13 .

A superhydrophobic membrane surface could reduce membrane wetting. To satisfy this purpose, plasma reactor was used to improve the surface hydrophobicity of the membranes ${ }^{14}$. Lin et al. achieved a water contact angle of $155^{\circ}$ with treated flat-sheet PVDF membranes in a plasma reactor using $\mathrm{CF}_{4}{ }^{15}$. They observed that the $\mathrm{CO}_{2}$ absorption fluxes increased by $7 \%$ and $17 \%$ relative to untreated PVDF and PTFE, respectively when using $1 \mathrm{M}$ AMP as an absorbent. The improvement is attributed to an increase in the elemental fluorine-to-carbon ratio, which reduces the membrane surface energy.

An alternative technique involving the deposition a rough layer on the membrane surface could yield a low-cost, porous and superhydrophobic surface. This technique was applied to eliminate the membrane wetting influence on the deterioration in the performance of $\mathrm{CO}_{2}$ absorption flux. A superhydrophobic PP flat sheet surface with a $169^{\circ}$ contact angle $\left(42^{\circ}\right.$ greater than plain PP) was fabricated by Franco et al. using methyl ethyl ketone (MEK) and cyclohexanone as non-solvent additives in a PP/xylene mixture ${ }^{16}$. The same non-solvents were considered by $\mathrm{Lv}$ et al. to improve the outer surface of PP hollow fiber membranes for $\mathrm{CO}_{2}$ absorp$\operatorname{tion}^{17}$. The membrane achieved a contact angle of $158^{\circ}$ and demonstrated good stability during a lengthy $\mathrm{CO}_{2}$ absorption operation when using 1M MEA.

In the present study, superhydrophobic membrane surface was fabricated using simple and low cost approach (dip coating). PVDF hollow fiber membranes were selected as a base surface because of their low assembly cost. Acetone and ethanol were adopted to prepare a low-cost non-solvent mixture. LDPE was used 
due to low dissolving temperature in xylene compared to PP. Contact angle, SEM, and AFM examinations were performed to assess the surface behavior in terms of porosity and hydrophobicity.

\section{EXPERIMENTAL}

\section{Materials}

Commercial-grade PVDF hollow fibers supplied by Pall Co. (UMP-153) were used in all experiments. Xylene ( $\geq 98.5 \%$ mixture of isomers + ethyl benzene basis) (Sigma-Aldrich) was used to dissolve commercial low-density polyethylene (LDPE) produced by Petlin Ld., Malaysia. Acetone $(\geq 99.8 \%)$ and ethanol $(\geq 99.9 \%)$ were purchased from Merck and used as non-solvents.

\section{Preparation of superhydrophobic surface}

LDPE polymer pellets were dissolved slowly in xylene (concentration of $10 \mathrm{mg} \cdot \mathrm{mL}^{-1}$ ) without any further treatment at $85^{\circ} \mathrm{C}$ using a heating mantle with stirring with a magnetic stirrer until the polymer dissolved completely. Hollow fiber ends were closed by chemical resistant epoxy to prevent the coating solution to come inside the lumen. At room temperature, the PVDF hollow fiber was immersed in the non-solvent solution for $30 \mathrm{~s}$ followed by LDPE solution for $10 \mathrm{~s}$. The sample was then dried under vacuum at room temperature for 2 hours.

\section{Field emission electron microscopy (FESEM) tests}

Field emission electronic microscopy (ZEISS SUPRA $35 \mathrm{VP}$ ) was used to investigate the surface and cross-section morphology of treated and untreated PVDF hollow fibers. The samples were fractured cryogenically and sputter-coated with platinum before testing.

\section{Atomic force microscopy (AFM)}

An atomic force microscope (Park System XE100, Korea) was used to examine the surface morphology of the created layer. The samples were observed under room temperature by AFM operated in the tapping mode to obtain the images with a scan size of $10 \mu \mathrm{m} \times 10 \mu \mathrm{m}$.

The roughness parameters obtained from AFM analysis software, such as the mean roughness $\left(R_{a}\right)$ and the standard deviation of the height value in the selected area $\left(R_{q}\right)$, were used to assess the effect of the modification method. The calculations of these parameters have been discussed in more detail by Stamatialis et al. and Chung et al. ${ }^{\mathbf{1 8}, 19}$.

\section{Water contact angle measurement}

A contact goniometer (Rame-Hart 250-F1, USA) was used to measure the contact angle between the distilled water drop and the outer surface of the PVDF hollow fiber membranes. The distilled water (volume) was dropped on the external membrane surface using a syringe. The contact angles were estimated using Rame-Hart image processing software. The reported contact angle was an average of five measurements at different positions on the membrane surface to eliminate measurement error.

\section{Porosity measurement}

Five untreated and five treated 3-cm-long PVDF hollow fibers were used to measure the overall porosity $\left(\varepsilon_{o}\right)$.The membranes were dried in an oven at $50^{\circ} \mathrm{C}$ for 24 hours, then the fibers were left to cool down before weighing them separately using a balance $\left(W_{d}\right)$. The hollow fiber was immersed in n-propanol for $15 \mathrm{~min}$. It was drained off until no visible solution was seen on the surface, then it was weighed again $\left(W_{w}\right)$. The total porosity was averaged for five fibers which can be obtained $\mathrm{as}^{\mathbf{2 0}}$ :

$\varepsilon_{o}(\%)=\frac{\left(W_{w}-W_{d}\right) / \rho_{i}}{\left(\frac{W_{w}-W_{d}}{\rho_{i}}\right)+\left(\frac{W_{d}}{\rho_{p}}\right)} \times 100$

where $\rho_{i}$ is the density of isopropanol, and $\rho_{p}$ represents the density of PVDF, which is $1.77 \mathrm{~g} / \mathrm{cm}^{3} \mathbf{1 2}^{\rho}$.

\section{Experimental setup for the $\mathrm{CO}_{2}$ absorption process}

Three modified hollow fibers were packed in a glass housing in a triangular arrangement, held by a perforated rubber stopper and sealed with epoxy resins at the module ends. Two Teflon flanges were put on both sides of the membrane module to avoid leakage during the experiments. The specifications of the modules are listed in (Table 1).

Table 1. Hollow fiber membrane module specifications

\begin{tabular}{|l|c|c|}
\hline Specification & $\begin{array}{c}\text { Non-modified } \\
\text { membrane }\end{array}$ & $\begin{array}{c}\text { Modified } \\
\text { membrane }\end{array}$ \\
\hline Module i.d $(\mathrm{cm})$ & 2.63 & 2.63 \\
\hline Fiber o.d. $(\mu \mathrm{m})$ & 3600 & 3602.68 \\
\hline Fiber i.d. $(\mu \mathrm{m})$ & 2400 & 2400 \\
\hline $\begin{array}{l}\text { Fiber length } \\
(\mathrm{cm})\end{array}$ & 18 & 18 \\
\hline $\begin{array}{l}\text { Number of } \\
\text { fibers }\end{array}$ & 3 & 3 \\
\hline Porosity $(\%)$ & 65.8 & 64.5 \\
\hline
\end{tabular}

A schematic diagram of the experimental setup is shown in (Fig. 1). A gas mixture of $20 \%$ (v/v) $\mathrm{CO}_{2}$ in $\mathrm{N}_{2}$ gas was introduced into the lumen side of the membrane module at $143 \mathrm{kPa}$. The gas flow rate was adjusted using a mass flow controller (AALBORG 0-500 ml/min), and the gases were then passed through a gas static mixer before flowing through the module. A 1M MEA liquid absorbent was pumped to the shell side using a digital peristaltic pump (Cole-Parmer, MasterFlex L/S) at 160 $\mathrm{kPa}$ to avoid the formation of bubbles in the liquid phase, which would lead to a non-uniform mass transfer interface on the superhydrophobic surface. The flow rate of the MEA solution was controlled by a rotameter with a counter-current flow to the gas flow. Samples of the outlet gas were collected and analyzed by gas chromatography (GC) (Shimadzu GC-2014).

\section{Absorption rate of $\mathrm{CO}_{2}$}

The efficiency of hollow fiber membrane modules for gas absorption in terms of the $\mathrm{CO}_{2}$ mass transfer flux was calculated as ${ }^{21}$.

$I_{\mathrm{CO}_{2}}=\frac{\left(Q_{g, \text { in }} \times C_{g, \text { in }}-Q_{g, \text { out }} \times C_{g, \text { out }}\right) \times 273.16}{0.0224 \times T \times S}$

where $J_{\mathrm{CO}_{2}}$ is the mass transfer flux of $\mathrm{CO}_{2}, \mathrm{~mol} \cdot \mathrm{m}^{-2} \cdot \mathrm{s}^{-1}$; $Q_{g \text {,in }}$ and $Q_{g, \text { out }}$ are the inlet and outlet gas flow rates, respectively, $\mathrm{m}^{3} \cdot \mathrm{s}^{-1} ; C_{g, \text { in }}$ and $C_{g, \text { out }}$ represent the volumetric rations of $\mathrm{CO}_{2}$ in the gas phase at the inlet and outlet, respectively, $\% ; T$ is the temperature of the gas, $\mathrm{K}$; and $S$ represent the gas-liquid interfacial area, $\mathrm{m}^{2}$. 


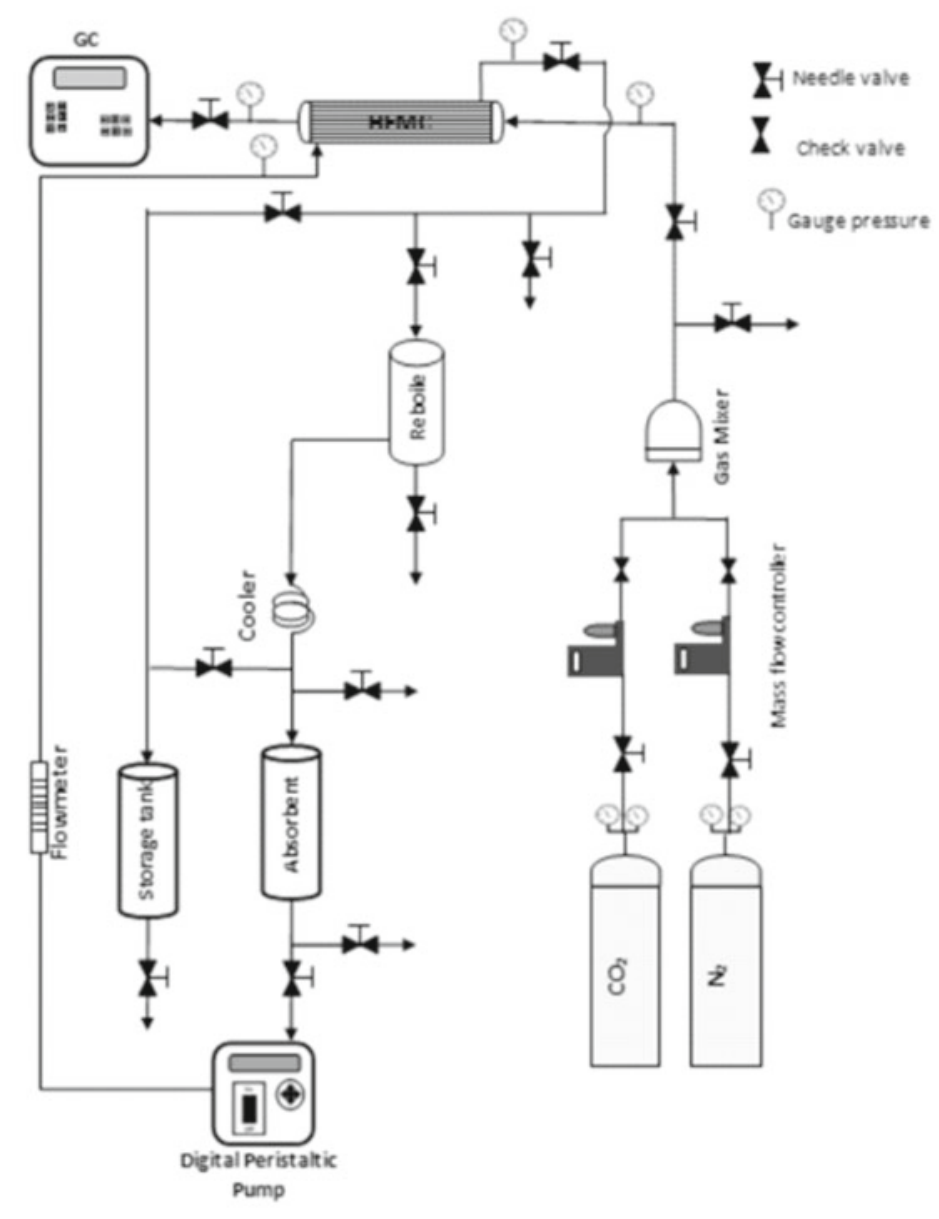

Figure 1. Schematic drawing of the experimental setup

\section{RESULTS AND DISCUSSION}

The SEM images as presented in (Fig. 2 a-d) indicate that acetone provided a rough surface with a high contact angle of $151.5^{\circ} \pm 2.6$, as shown in (Fig. 2 b). Despite the superhydrophobic surface, the pores were blocked almost completely.

The creation of the rough LDPE layer on the membrane surface may be attributed to the interfacial interaction between the solvent and non-solvent ${ }^{22}$. As the solvent and non-solvent diffused into each other and the tensions decreased, the originally smooth interface was partitioned into numerous curved interfaces. Finally, the tension of the curved interfaces was broken and the solvent contacted the non-solvent. Micro-phase separation takes place due to the precipitation of the LDPE in polymer solution on the membrane surface. The curved interface was further divided into smaller interfaces to create a fine nano-structure on the micro-papillae. The resulting surface morphology was lotus-like structure which is responsible to the high hydrophobicity.

Therefore, the solidification could occur rapidly, which was attributed to the high volatility of acetone, which reduces the pore formation and precipitation time of LDPE. This phenomenon was clearly observed during membrane treatment, wherein the membrane surface became opaque within 1 min after take out the sample from the coating solution. A low volatile non-solvent could increase the micro- and nano-scale aggregations of LDPE on the surface due to increase the polymer precipitation time. Ethanol $\left(78^{\circ} \mathrm{C}\right.$ boiling point) was blended with acetone $\left(56^{\circ} \mathrm{C}\right.$ boiling point) to afford sufficient time for pore configuration and LDPE precipitation. (Fig. $2 \mathrm{c}$ ) shows the porous membrane surface with a contact angle of $152^{\circ} \pm 3.2$ obtained when $5: 1(\mathrm{v} / \mathrm{v})$ acetone/ethanol is applied as the non-solvent. However, a higher ethanol content produces an inhomogeneous coating layer, as shown in (Fig. 2 d) for $5: 3(\mathrm{v} / \mathrm{v})$ acetone/ethanol, because of the instability of the coating solution on the membrane surface due to its curved shape before reaching the solidification step, leading to a low contact angle of $138.4^{\circ} \pm 3.7$. This finding agrees with the results of Lv et al. ,who observed significant cracking in the coated layer on a PP hollow fiber membrane when cyclohexane $\left(155.7^{\circ} \mathrm{C}\right.$ boiling point) was used ${ }^{17}$.

The roughness parameter was evaluated for the modified and plain membranes. The AFM examination results presented in (Table 2) which revealed that of the coated surface is 4.8 times higher than that of the un coated surface, as seen in the AFM image in (Fig. 3).

The modified and plain membranes were tested in a $\mathrm{CO}_{2}$ absorption system using 1 mol.L-1 MEA. The mass transfer flux outcomes exhibited good agreement with the characterization results. The initial flux was reduced for both membranes, which indicates that the additional $1.34-\mu \mathrm{m}$-thick rough layer in (Fig. $4 \mathrm{a}$ ) had little influence on the mass transfer resistance compared to the high resistance due to membrane wetting. The wetting effect during long-term operation was observed clearly after $24 \mathrm{hr}$. The reductions in the $\mathrm{CO}_{2}$ absorption flux for the plain and modified hollow fibers were approximately $43 \%$ and $16 \%$, respectively, as shown in (Fig. 5). 

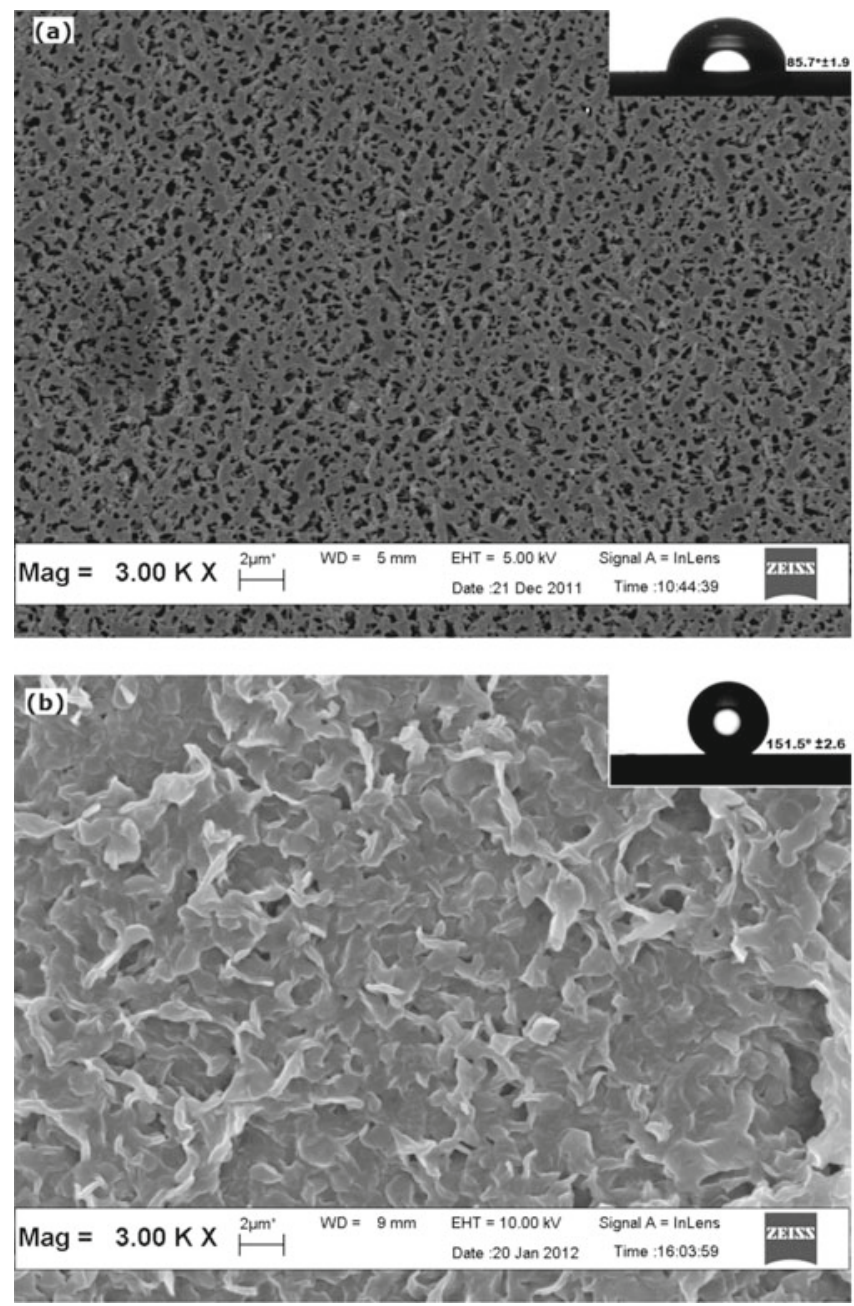
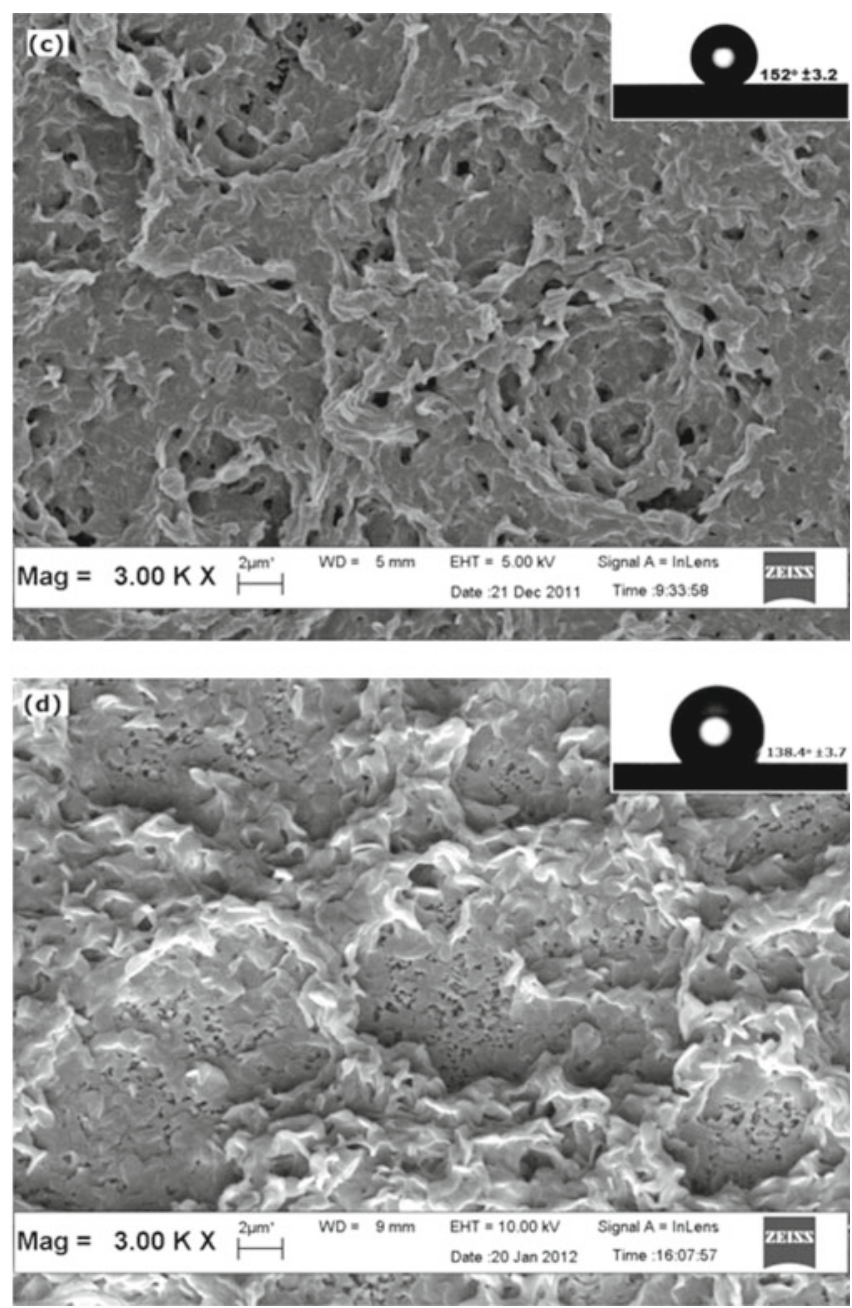

(c) PVDF treated with $5: 1(\mathrm{v} / \mathrm{v})$ acetone/ethanol; (d) PVDF treated with $5: 3(\mathrm{v} / \mathrm{v})$ acetone/ethanol

Table 2. Roughness parameters from AFM analysis software

\begin{tabular}{|l|c|c|}
\hline Surface Type & $\mathrm{R}_{\mathrm{a}}(\mathrm{nm})$ & $\mathrm{R}_{\mathrm{q}}(\mathrm{nm})$ \\
\hline Pristine Surface & 38 & 47 \\
\hline Superhydrophobic & 184 & 223 \\
\hline
\end{tabular}

This difference is attributed to the high contact angle of the modified membrane surface, which prevents the penetration of the liquid into the pores. After ten days of testing, both membranes exhibited different degrees of wetting. The flux declination in the plain membrane was largely increased at the initial stage relative to that of the modified membrane. The modified membrane exhibited a gradual reduction in the absorption flux due to the surface's ability to prevent the solvent from passing through the pores. (Fig. 4 b) showed that there was no pronounced change in the surface morphology after ten days of operation. The stability of the flux in modified membrane could be maintained for seven days of operation with partially wetted mode. On the other hand, the flux declination was continued in non-modified membrane and trended toward the fully-wetted mode. The wettability of the modified membrane has been tested by immersion in $1 \mathrm{~mol} \cdot \mathrm{L}^{-1}$ MEA solution for fifteen days, after which the contact angle was reduced by as little as $5^{\circ}$, indicating that the LDPE-modified membrane effectively retained its surface hydrophobicity. a)

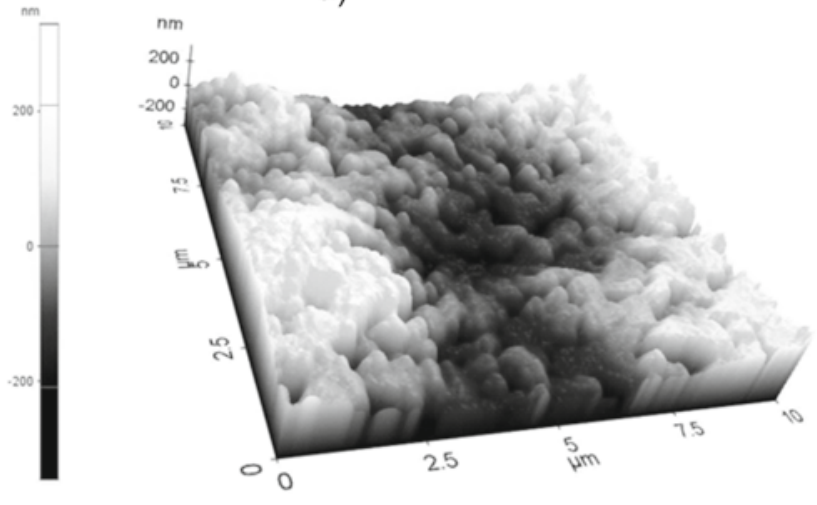

b)

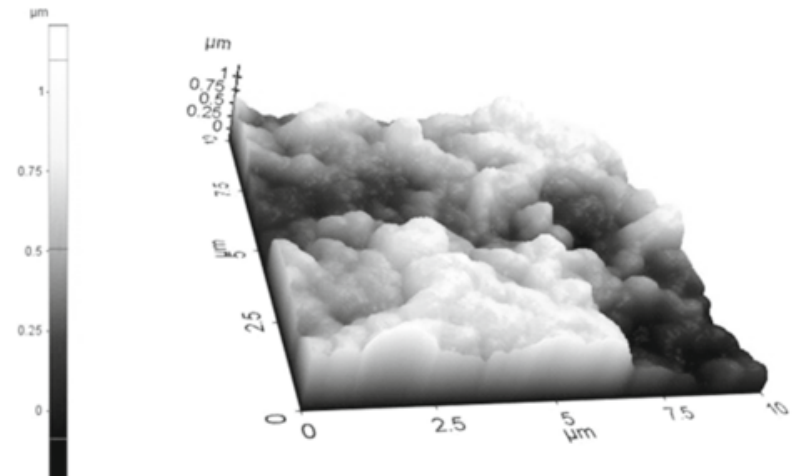

Figure 3. AFM image $10 \times 10 \mu \mathrm{m}$ for (a) plain membrane; (b) modified membrane 

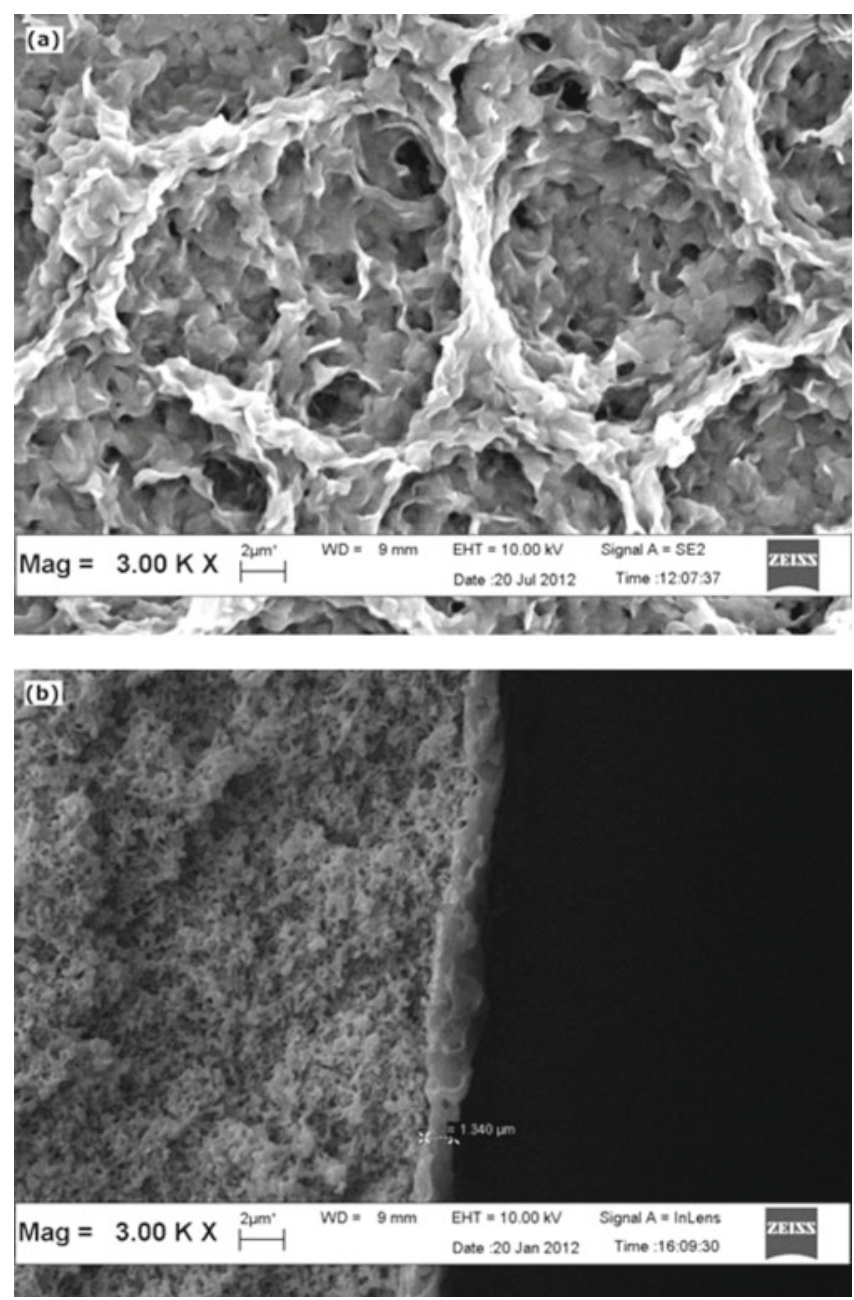

Figure 4. (a) Cross section of the modified hollow fiber using $5: 1(\mathrm{v} / \mathrm{v})$ acetone/ethanol; (b). FESEM for the modified membrane after testing in the absorption rig

\section{CONCLUSIONS}

A porous superhydrophobic layer has been fabricated on the PVDF hollow fiber membrane surface by a simple approach to increase the membrane wetting resistance. The solution of LDPE dissolved in xylene was used with different non-solvent mixtures of acetone and ethanol. Acetone, which has a low boiling point, produces a contact angle of $151.5^{\circ} \pm 2.6$ with low surface porosity. The blend of acetone/ethanol allows sufficient time for pore formation. The porous superhydrophobic layer generated from $10 \mathrm{mg} \cdot \mathrm{mL}^{-1} \mathrm{LDPE} / \mathrm{xylene}$ and $5: 1(\mathrm{v} / \mathrm{v})$ acetone/ ethanol non-solvent exhibits a $152^{\circ} \pm 3.2$ contact angle and a mean roughness that is 4.8 times greater than the original layer. In addition, the total porosity of the modified membrane was only slightly decreased $(1.3 \%)$. The reduction in the $\mathrm{CO}_{2}$ absorption flux for the high contact angle is $14 \%$ after 1 day of operation and stabilizes after seven days. In contrast, the plain membrane lost $43 \%$ of its initial flux over the same time period, with a continuous decline with time.

\section{Acknowledgments}

The authors wish to thank the financial support granted by MOSTI Science Fund (No. 305/PJKIMIA/6013386), FRGS fund (No. 203/PJKIMIA/6071234), RU-PRGS fund (No. 1001/PJKIMIA/8045029) and Universiti Sains Malaysia Membrane Science and Technology Cluster.

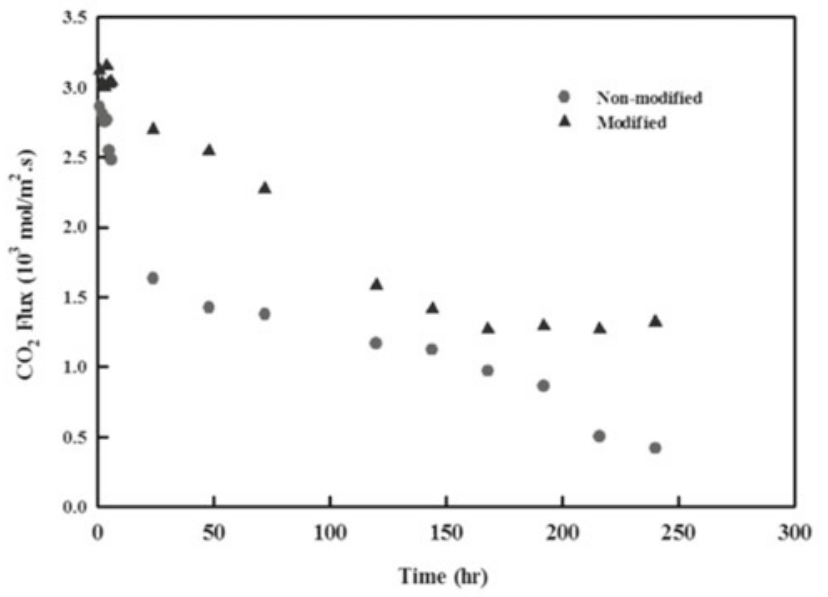

Figure 5. Behavior of $\mathrm{CO}_{2}$ mass transfer flux for plain and modified membranes $\left(Q_{l, \text { in }}=50 \mathrm{ml} / \mathrm{min}, Q_{g, \text { in }}=150 \mathrm{ml} /\right.$ $\min , C_{g, i n}=20 \%$, absorbent concentration is $1 \mathrm{~mol}$ $\mathrm{L}^{-1}$ MEA

\section{LITERATURE CITED}

1. Desideri, U. \& Paolucci, A. (1999). Performance modeling of a carbon dioxide removal system for power plants. Energy Convers. Manage. 40 (18), 1899-1915. DOI: 10.1016/S01968904(99)00074-6.

2. Qi, Z. \& Cussler, E.L. (1985). Microporous hollow fibers for gas absorption. Part 1: mass transfer in the liquid. J. Membr. Sci. 23 (3), 321-332. DOI: 10.1016/S0376-7388(00)83149-X.

3. Qi, Z. \& Cussler, E.L. (1985). Microporous hollow fibers for gas absorption. II. Mass transfer across the membrane J. Membr. Sci. 23 (3), 333-345. DOI: 10.1016/S0376-7388(00)83150-6.

4. Wang, R., Zhang, H.Y., Feron, P.H.M. \& Liang, D.T. (2005). Influence of membrane wetting on $\mathrm{CO}_{2}$ capture in microporous hollow fiber membrane contactors. Sep. Purif. Technol. 46 (1-2), 33-40. DOI: 10.1016/j.seppur.2005.04.007.

5. Ahmad, A.L., Sunarti, A.R., Teongl, L.K. \& Fernando, W.J.N. (2009). Development of thin film composite for $\mathrm{CO}_{2}$ separation in membrane gas absorption application. AsiaPac. J. Chem. Eng. 4 (5), 787-792. DIO: DOI: 10.1002/apj.339.

6. Rajabzadeh, S., Yoshimoto, S., Teramoto, M., Al-Marzouqi M. \& Matsuyama, H. (2009). $\mathrm{CO}_{2}$ absorption by using PVDF hollow fiber membrane contactors with various membrane structures. Sep. Purif. Technol. 69 (2), 210-220. DOI: 10.1016/j. seppur.2009.07.021.

7. Mansourizadeh, A., Ismail, A.F. \& Matsuura T. (2010). Effect of operating conditions on the physical and chemical $\mathrm{CO}_{2}$ absorption through the PVDF hollow fiber membrane contactor. J. Membr. Sci. 353 (1-2), 192-200. DOI: 10.1016/j. memsci.2010.02.054.

8. Ahmad, A.L., Sunarti, A.R., Lee, K.T. \& Fernando, W.J.N. (2010). $\mathrm{CO}_{2}$ removal using membrane gas absorption. Int. J. Greenh. Gas Control. 4 (3), 495-498. DOI: 10.1016/j. ijggc.2009.12.003.

9. Mansourizadeh, A. \& Ismail, A.F. (2011). Preparation and characterization of porous PVDF hollow fiber membranes for $\mathrm{CO}_{2}$ absorption: Effect of different non-solvent additives in the polymer dope. Int. J. Greenh. Gas Control. 5 (4), 640-648. DOI: 10.1016/j.ijggc.2011.03.009.

10. Atchariyawut, S., Jiraratananon, R. \& Wang, R. (2007). Separation of $\mathrm{CO}_{2}$ from $\mathrm{CH}_{4}$ by using gas-liquid membrane contacting process. J. Membr. Sci. 304 (1-2), 163-172. DOI: 10.1016/j.memsci.2007.07.030.

11. Nishikawa, N., Ishibashi, M., Ohta, H., Akutsu, N. \& Matsumoto, H. (1995). $\mathrm{CO}_{2}$ removal by hollow fiber gas-liquid contactors. Energy Convers Manage. 36 (6-9), 415-418. DOI: 10.1016/0196-8904(95)00033-A.

12. Mansourizadeh, A., Ismail, A.F., Abdullah, M.S. \& Ng, B.C. (2010). Preparation of polyvinylidene fluoride hollow 
fiber membranes for $\mathrm{CO}_{2}$ absorption using phase-inversion promoter additives. J. Membr. Sci. 355 (1-2), 200-207. DOI: 10.1016/j.memsci.2010.03.031.

13. Mansourizadeh, A. \& Ismail, A.F. (2010). Effect of LiCl concentration in the polymer dope on the structure and performance of hydrophobic PVDF hollow fiber membranes for $\mathrm{CO}_{2}$ absorption. Che. Eng. J. 165 (3), 980-988. DOI: 10.1016/j. cej.2010.10.034.

14. Su-Hsia, L., Kuo-Lun, T., Wei-Jie, C. \& Hao-Wei, C. (2009). Absorption of carbon dioxide by mixed piperazinealkanolamine absorbent in a plasma-modified polypropylene hollow fiber contactor. J. Membr. Sci. 333(1-2), 30-37. DOI: 10.1016/j.memsci.2009.01.039.

15. Su-Hsia, L., Kuo-Lun, T., Hao-Wei, C. \& Kueir-Rarn, L. (2009). Influence of fluorocarbon flat-membrane hydrophobicity on carbon dioxide recovery. Chemosphere, 75 (10), 1410-1416. DOI: 10.1016/j.chemosphere.2009.02.027.

16. Julianna, F.A., Sandra, E.K., Jilska, P.M. \& Geoff, S.W. (2008). Fabrication of a superhydrophobic polypropylene membrane by deposition of a porous crystalline polypropylene coating, J. Membr. Sci. 318 (1-2), 107-113. DOI: 10.1016/j. memsci.2008.02.032.

17. Lv, Y., Xinhai Y., Jingjing, J., Shan-Tung, T., Jinyue, Y. \& Erik, D. (2012). Fabrication and characterization of superhydrophobic polypropylene hollow fiber membranes for carbon dioxide absorption. App. Energy, 90 (1), 167-174. DOI: 10.1016/j.apenergy.2010.12.038.

18. Dimitris, S.F., Cristina, D.R. \& de Pinho, N.M. (1999). Atomic force microscopy of dense and asymmetric cellulosebased membranes. J. Membr. Sci. 160 (2), 235-242. DOI: 10.1016/S0376-7388(99)00089-7.

19. Tai-Shung, C., Jian-Jun, Q., Alfred, H. \& Kee-Chua, T. (2002). Visualization of the effect of die shear rate on the outer surface morphology of ultrafiltration membranes by AFM. J. Membr. Sci. 196 (2), 251-266. DOI: 10.1016/S03767388(01)00609-3.

20. Supakorn, A., Chunsheng, F., Rong, W., Ratana, J. \& Liang, D.T. (2006). Effect of membrane structure on masstransfer in the membrane gas-liquid contacting process using microporous PVDF hollow fibers. J. Membr. Sci. 285 (1-2), 272-281. DOI: 10.1016/j.memsci.2006.08.029.

21. Shui-ping, Y., Meng-Xiang, F., Wei-Feng, Z., Shu-Yuan, W., Zhi-Kang, X., Zhong-Yang, L. \& Ke-Fa, C. (2007). Experimental study on the separation of $\mathrm{CO}_{2}$ from flue gas using hollow fiber membrane contactors without wetting. Fuel Proce. Technol. 88 (5), 501-511. DOI: 10.1016/j.fuproc.2006.12.007.

22. Xinhong, L., Guangming, C., Yongmei, M., Lin, F., Hongzhi, Z., Lei, J. \& Fosong, W. (2006). Preparation of a super-hydrophobic poly(vinyl chloride) surface via solvent-non solvent coating. Polymer. 47 (2), 506-509. DOI: 10.1016/j. polymer.2005.08.097. 